\title{
Preparation of bitumen using acidic tars
}

\author{
Yuriy Khlibyshyn ${ }^{1}$, Iryna Pochapska ${ }^{2}$, Oleg Grynyshyn ${ }^{3}$, \\ Department of Organic Products Technology, Lviv Polytechnic National University, Ukraine, Lviv, 3/4 St. Yura \\ square, Building 8, yurii.y.khlibyshyn@1pnu.ua
}

Department of Civil Safety, Lviv Polytechnic National University, Ukraine, Lviv, 1 St. Yura square, Building 3, iryna.y.pochapska@lpnu.ua

Department of Chemical Technology of Oil and Gas Processing, Lviv Polytechnic National University, Ukraine, Lviv, 3/4 St. Yura square, Building 8, ogrynyshyn@ukr.net

\begin{abstract}
The studies undertaken have established the effect of the ratio of acid tar coupled with straight-run petroleum tars introduced into the process. The influence temperature of the process, of final heating temperature of the bitumen mass in the reactor and of stirring intensity of the reaction mixture in the reactor on the quality is installed.
\end{abstract}

Keywords: acid tar, asphalt, bitumen, ductility, penetration

\section{Introduction}

Acid tar (AT) belong to the II class hazard waste. To date, there are no universal technologies for their complex processing. This creates serious difficulties in the disposal of storage ponds AT. The acid tars are wastes from oil refining and petrochemical industries that are troublesome for disposal. They are formed during purification of special oils such as condenser, transformer, hydraulic, medical, perfumery oil, etc., as well as in production of flotation reagents and additives, in sulfonation of individual hydrocarbons and petroleum fractions. [1,2]. AT are occupy the second place in the accumulation after oil sludge. According to the physico-chemical composition - it is a gum-like tall bulk mass containing various organic compounds, sulfuric acid and water.

Acid tars are pose an environmental hazard in that their chemical composition does not actually allow direct consumption, because that acid tars are dumped in gathering ponds, as results, is have create a significant environmental hazard without proper utilization. With such methods used for ATs disposal, environmental pollution occurs, leading to acidification of soil and water bodies, and, consequently, to destruction of flora and fauna. A natural continuous oxidation-reduction process causes the release of a large amount of sulfur dioxide, which, in turn, contaminates the air basin. The acid tar ponds are prompted on vast areas thens contain thousands of tons of wastes with the total mass in Ukraine and abroad reaching millions of tons. Thus, only on the territory of Lviv region not less than 150 thousand $\mathrm{m}^{3}$ of acid tars are found [3, 6].

Over a long period of use in the petroleum industry method of cleaning oil sulfuric acid recycling is propose realizing in many options that create acidic tars. This is because the acid tars, as already mentioned, are dangerous to the environment and pose significant environmental problems. Also, in the tanks of acid dusts, a large amount of hydrocarbons and other compounds are concentrated, which, of course, must be utilized for industrial use [4]. Modern technologies for ATs disposal according to the influence on wastes are as follows:

- pyrolysis under the influence of high temperatures $\left(800-1200{ }^{\circ} \mathrm{C}\right)$ producing $\mathrm{H}_{2} \mathrm{SO}_{4}$, heat, high-sulfur coke, activated carbon [5];

- low temperature decomposition within 150 - $350^{\circ}$ followed by bitumen generation [6];

- water or steam hydrolysis producing dilute $\mathrm{H}_{2} \mathrm{SO}_{4}$ and fuel components; 
- neutralization by various agents with the receipt of fuel, surfactants, or for waste disposal [7].

\section{Experimental}

The purpose of the study was to identify the influence of various parameters on treatment of acid tar that has been dumped in lagoons for a long time by turning it into petroleum-based bitumen [8].

To achieve a target goal, the following tasks were solved:

- to determine the influence on the qualitative characteristics of bitumen and smoothness of the process, that is, the ratio of acid tar to straight-run tar taken into the process; temperature of the process; specific feed rate of acid tar to the reactor; rate of temperature rise in the reactor; final heating temperature of the bituminous mass in the reactor and the intensity at which the reaction mixture is mixed in the reactor;

-to establish optimal conditions for acid tar treatment with conversion to petroleum-based bitumen.

The bituminous mass is generated from a mixture of acid and straight-run tars when they are simultaneously heated. At the same time oxidation occurs with sulfuric acid as the organic mass at elevated temperatures appears to be a reducing medium for sulfuric acid. The resulting sulphuric anhydride oxidizes an organic matter, turning it into bituminous mass. The quality and yield of bitumen and the smoothness of the process can be affected by a significant number factors.

The following main parameters of the properties of obtained bitumens were ductility, penetration, softening point and solubility in an organic solvent (benzene).

Studies have indicated that with increasing content in the mixture of acidic tar, the softening temperature increases, while the ductility and penetration decreases.

The study showed that the initial temperature in the reactor core has little effect on bitumen quality indicators: softening temperature, ductility, penetration, solubility in benzene content of water-soluble compounds, acids and alkalis. However, the initial temperature in the reactor affects the flow of the process. As the temperature in the reactor rises above $160{ }^{\circ} \mathrm{C}$, increased foam generation together with a marked increase in the reaction mass is observed. So when acid tars is fed to straight-run tar that is heated above $100{ }^{\circ} \mathrm{C}$, the reaction of sulfuric acid with the most reactive components of tar initiates. The acid tar feed to the reactor at a temperature above $200{ }^{\circ} \mathrm{C}$ serves to obtain the bitumen in which the homogeneity is disturbed and available consolidating products are in the form of small grains. Studies have shown that the specific feed rate of acid tar to the reactor has no decisive impact on the quality of the resulting bitumen. Increasing specific feed rate of acid tar causes process intensification, an increase in gas release and foam formation.

According to the study, the process of obtaining bitumen from a mixture of acid and straight-run tars can be performed when they are mixed on one occasion by the temperature of the mixture that should be lower than $100{ }^{\circ} \mathrm{C}$. It should be noted that the next mixture heating has to be at the rate of temperature rise within $1.5-2{ }^{\circ} \mathrm{C} / \mathrm{min}$, then vapor liberation and foam generation are found to be less intense, and the reaction volume is increased only by 2-3 times.

It is to be admitted, however, that straight and acid tars are substances of high viscosity, and, therefore, the intensity of mass transfer will significantly affect the intensity and smoothness of the process. So then, mixing is an obligatory condition to conduct the process. Mixing intensity that underwent examination in the range of 50 to 250 turns per minute showed no such effect on the quality of the obtained bitumens at equal initial conditions. The results suggest the 
following: if not mixed a low-quality heterogeneous bituminous mass is produced; and asphaltenes that are formed due to high molecular weight and high adhesion are precipitated on the walls of the reactor. As a result, with exposure to high temperature, asphaltenes are carbonized being turned into a low-soluble product that impedes the heating of the entire reaction mass. On the other hand, the mixing process enables not only to avoid precipitation of asphaltenes but also reduces the foam formation and the volume of the reaction mass.

The technological features of using acid tar in the bitumen production have been examined and the optimal conditions of the process have been established, such as the acid tar content is $20-35 \%$ in the mixture, final heating temperature of the bituminous mass is equal to 300-320 $\circ$, the specific feed rate of acid tar in the mixture amounts to $2.5-6 \mathrm{~g} /(\mathrm{min} \times \mathrm{kg})$, the rate of temperature rise in the reactor is represented by $2-5{ }^{\circ} \mathrm{C} / \mathrm{min}$. The first two factors have a significant effect on the quality of bitumens, while others on the smoothness of the process.

\section{Conclusion}

The results of the research suggest the following: poor quality is obtained without mixing heterogeneous mass bitumen and asphaltenes formed as a result of high molecular weight and high adgesion are deposited on the walls of the reactor. As a result, asphaltenes are exposed to high temperature and carbolization, becoming insoluble product that prevents heating of the entire mass. However, mixing allows not only to avoid sedimentation of asphaltenes, but also reduces foaming reaction mass and volume.

\section{References}

[1] Leonard, S.A., Stegemann, J.A., Roy A. Characterization of acid tars // Journal of Hazardous Materials. - 2010. - Vol. 175. - № 1-3. - P. 382-392.

[2] Jafari A.J., Hassanpour M., Farzadkia M. Economic evaluation of recycling acidic sludge project of reprocessing industries to bitumen // Environmental Technology \& Innovation, 2016 - №5. - P.30-40.

[3] Topilnytskyi P.I., Pryvarska M.I., Romanchuk V.V., Didun E.O. Problemy utylizatsii stavkovykh kyslykh hudroniv // Tezy dop. 2-ho Mizhn. Konhresu "Zakhyst navkolyshnoho seredovyshcha. Enerhooshchadnist. Zbalansovane pryrodokorystuvannia”. - Lviv. - 2012. - P. 66.

[4] Lotosh V.E. Pererabotka otkhodov pryrodopolzovanyia. - Ekaterynburr: Polyrpafyst, 2007. -503 p.

[5] Thermal cracking of acid tars to asphalts as a process for utilization of refinery wastes / G. A. Kolmakov, V.F. Zanozina, .N. Karataev, D.F. Grishin, A.D. Zorin // Petroleum Chemistry. - 2006. - Vol.46. -№ 6, - P.384-388.

[6] Fryder I.V., Topilnytskyi P.I., Hrynyshyn O.B. Vykorystannia kyslykh hudroniv u vyrobnytstvi naftovykh bitumiv //Visnyk Natsionalnoho universytetu "Lvivska politekhnika". Khimiia, tekhnolohiia rechovyn ta yikh zastosuvannia. - 2013. - № 761. P.452-457.

[7] Environmental aspect of storage of acid tars and their utilization in commercial petroleum products (Review) / G.A. Kolmakov, D.F. Grishin, A.D. Zorin, V.F. Zanozina // Petroleum Chemistry. - 2007. - Vol. 47. - №6. - P.379-388.

[8] Y. Khlibyshyn, I. Pochapska, O. Grynyshyn, Z. Gnativ. The study of the fabrification of bitumen from acid tars and oil residues // ит ння хімії т хімічної технології. - 2018. № 5 (120). - . 161-167. 